\title{
Torção uterina em vacas leiteiras: relato de 24 casos
}

Ana Clara Sarzedas Ribeiro ${ }^{[]^{*}}$, José Augusto Bastos Afonso ${ }^{[b]}$, Nivaldo de Azevedo Costa $a^{[b]}$, Carla Lopes de Mendonça[a], Rodolfo José Cavalcanti Souto ${ }^{[b]}$, Nivan Antônio Alves da Silva ${ }^{[b]}$, Maria Isabel de Souza ${ }^{[b]}$, Luiz Teles Coutinho ${ }^{[b]}$, Jobson Filipe de Paula Cajueiro[b]

[a] Programa de Residência em Sanidade de Ruminantes, Clínica de Bovinos, Universidade Federal Rural de Pernambuco (UFRPE), Garanhuns, PE, Brasil

[b] Clínica de Bovinos, Universidade Federal Rural de Pernambuco (UFRPE), Garanhuns, PE, Brasil

*Autor correspondente

e-mail: ac_sarzedas@id.uff.br

\section{Resumo}

A torção uterina é o movimento rotacional do órgão gestante sobre o seu eixo longitudinal, sendo mais frequente na vaca do que em qualquer outra espécie. A sua etiopatogenia ainda não está bem elucidada, mas estão entre os fatores de riscos: movimento fetal excessivo nos estágios iniciais do parto, excesso de peso fetal, abdômen mais profundo em algumas raças, senilidade e número de partos, causando flacidez da musculatura e ligamentos uterinos. 0 diagnóstico é baseado no exame obstétrico, através da palpação vaginal e/ou transretal. 0 prognóstico depende do grau da rotação, do tempo de evolução e das sequelas sobre o útero e o feto. Neste contexto, objetiva-se descrever aqui a ocorrência e a análise de alguns fatores relacionados à torção uterina em vacas atendidas na Clínica de Bovinos de Garanhuns - Universidade Federal Rural de Pernambuco (CBG/UFRPE), nos anos de 2015 e 2016. Os partos representaram 21,36\% (210/983) da casuística de bovinos neste período, dos quais 9,05\% (19) foram eutócicos e 90,95\% (191) distócicos. Quanto às distocias, 49,21\% (94) foram fetais, 38,22\% (73) maternas e 12,57\% (24) maternofetais. Foram atendidos 24 casos de torção uterina (11 em vacas multíparas, 10 primíparas e em três casos esta informação foi omitida), o que representou 12,57\% de todas as distocias e 32,88\% das maternas. Foram constatadas rotações de $90^{\circ}(13,04 \%), 180^{\circ}(43,48 \%)$ e $\geq 360^{\circ}(43,48 \%)$. A correção da torção uterina foi realizada através de cesariana em 17 casos (70,83\%) e em três casos (12,5\%) por meio de laparotomia com manipulação uterina, seguida de manobra obstétrica. Um animal apresentou torção de útero no segundo dia pós-cirúrgico de cesariana, sendo a mesma corrigida através de laparotomia. Em virtude da inviabilidade materno-fetal, indicou-se a eutanásia de três animais. Em 64,7\% das cesarianas não foi possível luxar o útero, devido ao seu comprometimento vascular, portanto, realizou-se a histerotomia na cavidade abdominal. 
A gestação foi simples (um feto) em todos os casos e 66,67\% dos fetos estavam mortos, 28,57\% vivos e $4,76 \%$ natimortos. Quanto ao desfecho, 17 animais $(70,83 \%)$ receberam alta clínica e sete vieram a óbito $(29,17 \%)$. Em três casos os fetos encontravam-se enfisematosos, destes duas vacas morreram e uma foi eutanasiada. Os achados anatomopatológicos foram: peritonite serofibrinosa difusa e lacerações uterinas. A torção uterina representou uma relevante causa de distocia materna na rotina hospitalar da CBG/UFRPE, neste período. 0 comprometimento vascular causado pela torção pode tornar o útero friável, predispondo-o à ruptura. Nas situações em que os fetos já se apresentarem enfisematosos o prognóstico é ruim, pelo alto risco de ruptura uterina, hemorragias e peritonite. Por tratar-se de uma emergência obstétrica, o diagnóstico correto da torção uterina é fundamental, devendo-se considerar a condição clínica da parturiente e do feto para determinação do tratamento e do prognóstico. 